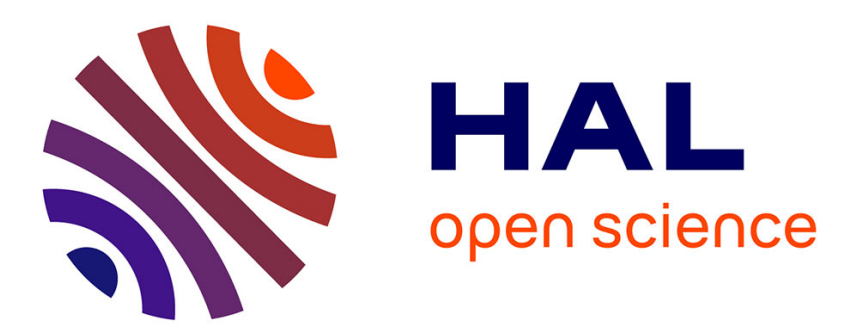

\title{
Microstructure evolution of hot-work tool steels during tempering and definition of a kinetic law based on hardness measurements
}

\author{
Z Zhang, Denis Delagnes, Gérard Bernhart
}

\section{To cite this version:}

Z Zhang, Denis Delagnes, Gérard Bernhart. Microstructure evolution of hot-work tool steels during tempering and definition of a kinetic law based on hardness measurements. Materials Science and Engineering: A, 2004, 380 (1-2), pp.222-230. 10.1016/j.msea.2004.03.067 . hal-01715086

\author{
HAL Id: hal-01715086 \\ https://hal.science/hal-01715086
}

Submitted on 11 Jan 2019

HAL is a multi-disciplinary open access archive for the deposit and dissemination of scientific research documents, whether they are published or not. The documents may come from teaching and research institutions in France or abroad, or from public or private research centers.
L'archive ouverte pluridisciplinaire HAL, est destinée au dépôt et à la diffusion de documents scientifiques de niveau recherche, publiés ou non, émanant des établissements d'enseignement et de recherche français ou étrangers, des laboratoires publics ou privés. 


\title{
Microstructure evolution of hot-work tool steels during tempering and definition of a kinetic law based on hardness measurements
}

\author{
Z. Zhang ${ }^{\mathrm{a}, *}$, D. Delagnes ${ }^{\mathrm{b}}, \mathrm{G}$. Bernhart ${ }^{\mathrm{b}}$ \\ a Institute of Materials and Technology, Dalian Maritime University, Dalian 116026, China \\ ${ }^{\mathrm{b}}$ Research Centre on Tools, Materials and Processes (CROMeP), Ecole des Mines d'Albi-Carmaux, 81013 Albi CT cedex 09, France
}

\begin{abstract}
Microstructural evolutions of the $55 \mathrm{NiCrMoV7}$ steel during tempering were investigated by transmission electron microscopy, scanning electron microscopy and X-ray diffraction in order to describe the main mechanisms of softening. The softening resistance is strongly associated with evolution of obstacles to the movement of dislocations (prior austenitic grain boundary, lath boundary, secondary carbides, etc.). Only the average size of carbides was found to be influenced by tempering conditions. Moreover, a strong correlation observed between the hardness measured after tempering and the average size of carbides showing that this easy test could in this case partially characterize the state of the microstructure after tempering. Performing hardness measurements at the as-quenched, tempered and annealed states, a kinetic law of tempering based on the work of Johnson, Mehl and Avrami has been proposed. This law was validated in the case of complex tempering and for other steels and can well describe the evolution of hardness during tempering.
\end{abstract}

Keywords: Martensitic steel; Kinetic law of tempering; Tempering ratio; Microstructure; Carbides; Hardness

\section{Introduction}

Hot-work tool steels are widely used at various tempering states with different mechanical properties, according to the needs of industrial applications where the steel endures cyclic thermal and mechanical loads. Furthermore, some investigations [1-3] have shown that the temperature at the surface of the tool may exceed the tempering temperature. In that case, the steel may be subjected to a continuous evolution of the microstructure and associated properties during service. As a consequence, it is important to understand the evolution of the microstructure during tempering and during service in order to control the tool lifetime. Therefore, researchers have paid close attention to the evolution of microstructure and properties with time and temperature over a long period of time. For example, relationships between the microstructure obtained after tempering and physical properties have been widely studied [4-6]. In that field, Engel finely investigated the softening rate of steel when

\footnotetext{
* Corresponding author. Tel.: +86-411-4726897; fax: +86-411-4727184

E-mail address: zzp@newmail.dlmu.edu.cn (Z. Zhang).
}

tempered from different initial structures. In other respects, relations between time, temperature and composition with the microstructure obtained after tempering have also been intensively investigated [7-15].

Without any doubt, the famous work of Hollomon and Jaffe has led to the most well known relation. Hollomon and Jaffe [10] supposed that the same hardness could be reached by different tempering history, i.e. by different time-temperature routes assuming that the hardness was a function of the time and the temperature: hardness $=$ $f\left(t e^{-Q / R T}\right)$. Finally, Hollomon and Jaffe have obtained a relation between the hardness and a tempering parameter $M$ : hardness $=f(M)=f[T(c+\log t)]$. This relation has a great importance and has been widely used to determine the different possibilities of tempering conditions in industry. But, as this relation is not a kinetic law (hardness is not an explicit function of time and temperature), this relation cannot describe the evolution of hardness during a tempering and cannot be used to predict the hardness variation of steels in service with time and temperature. Moreover, some authors indicated that the Hollomon-Jaffe relation is not suitable for all steels [11-16]. In order to extend the application of the Hollomon and Jaffe work, some re- 


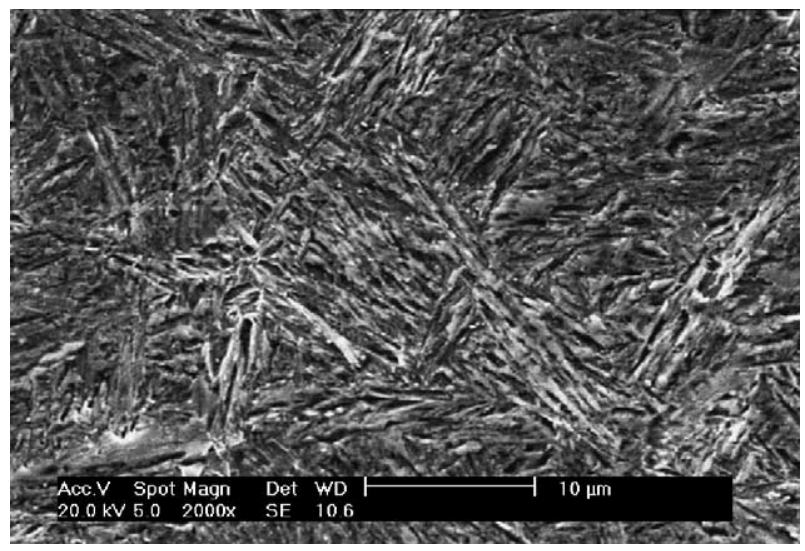

Fig. 1. SEM micrograph of the as-quenched microstructure.

searchers [11-15] have proposed some modifications of the initial law. For example, with a reference state tempered at $550{ }^{\circ} \mathrm{C}$ for $2 \mathrm{~h}$ and $600{ }^{\circ} \mathrm{C}$ for $2 \mathrm{~h}$, Jean [15] gave a relative hardness decrease law with time and temperature for $5 \%$ chromium hot-work tool steel.

In this study, our aim is to develop a kinetic law describing the softening of the steel during tempering. At first, the steel investigated and experimental methods are presented. Then, after the study of microstructural evolutions during tempering at different scales (ex-austenitic grains, martensitic laths and carbides), a kinetic law of tempering is proposed. This law is based on microstructural investigations of secondary carbides growth and the associated hardness evolution. In the last part, this kinetic law is discussed in detail using data coming from the literature obtained on different types steels.

\section{Materials and experiments}

\subsection{NiCrMoV7 steel}

The grade investigated is the $55 \mathrm{NiCrMoV} 7$ hot-work tool steel with the following chemical composition (wt.\%): $0.56 \mathrm{C}, 1.7 \mathrm{Ni}, 1.0 \mathrm{Cr}, 0.5 \mathrm{Mo}, 0.1 \mathrm{~V}, 0.2 \mathrm{Si}$ and $0.7 \mathrm{Mn}$. The microstructure obtained after quenching is shown in Fig. 1. The quenched microstructure contains martensitic laths and a small quantity of primary carbides. In addition, no retained austenite was detected by X-ray diffraction (XRD).
Table 1

Heat treatment conditions for the analysis of ex-austenitic grains and tempered martensitic lath sizes

\begin{tabular}{lll}
\hline Sample & Quenching & Tempering \\
\hline R52 & Austenizing to $875^{\circ} \mathrm{C}$ for $1 \mathrm{~h}$ oil quenching & $510^{\circ} \mathrm{C}+2 \mathrm{~h}$ \\
R63 & Austenizing to $875^{\circ} \mathrm{C}$ for $1 \mathrm{~h}$ oil quenching & $605^{\circ} \mathrm{C}+3.5 \mathrm{~h}$ \\
\hline
\end{tabular}

\subsection{Experiments}

Heat treatment conditions for the analysis of ex-austenitic grains and martensitic laths are presented in Table 1. Heat treatment conditions for hardness measurements and for investigations of the relationship between hardness and secondary carbides are shown in Table 2. Thermocouples for temperature control were welded on each sample. Vickers hardness measurements were performed on every sample after the tempering. Considering the experimental schedule, 15 samples of the part 1 were used to investigate the evolution of the volume fraction of carbides, 8 samples indicated by bold type numbers were selected on the basis of the Hollomon-Jaffe relation $T(20+\log t)=$ constant for the steel, and finally the 6 samples indicated by numbers with an asterisk were devoted to the determination of the evolution of the mean carbide size during tempering.

The microstructure evolution of the steel was investigated by XRD, scanning electron microscopy (SEM) PHILIPS XL30, transmission electron microscopy (TEM) JEOL 2010 and PHILIPS CM12 and quantitative image analysis. Quantitative image analysis was carried out with the software VISILOG ${ }^{\circledR}$. In order to reveal respective lath and prior austenitic grain boundaries, samples were respectively etched $3 \mathrm{~s}$ with a Nital $2 \%$ solution ( $2 \%$ nitric acid+ethanol) and $16 \mathrm{~h}$ with the corrosive Beaujard-Bechet solution $(4 \%$ picric acid $+1 \%$ Teepol aqueous solution). The morphology and the mean size of ex-austenitic grain and martensitic lath were investigated by SEM observations and quantitative image analysis. The volume fraction of the carbides was estimated by energy dispersive X-ray diffraction. The size and morphology of carbides were analyzed by TEM observations and quantitative image analysis. Previously, carbides were extracted from the martensitic matrix using the well-known replica technique [16].

Hardness measurements were performed using a Buehler ${ }^{\circledR}$ MICROMET ${ }^{\circledR} 2001$ type microhardness tester.

Table 2

Tempering conditions for hardness evolution measurements and carbides analysis

\begin{tabular}{|c|c|c|c|c|c|c|c|c|c|}
\hline \multirow[t]{2}{*}{ Tempering temperature $\left({ }^{\circ} \mathrm{C}\right)$} & \multicolumn{3}{|l|}{ Part 1} & \multicolumn{6}{|l|}{ Part 2} \\
\hline & \multicolumn{3}{|c|}{ Tempering time $(\mathrm{h})$} & \multicolumn{6}{|c|}{ Tempering time $(\mathrm{h})$} \\
\hline 350 & 0.25 & 2 & 665.00 & 0.025 & 0.083 & 0.5 & 1 & 75 & 189 \\
\hline 460 & 0.25 & 2 & 25.63 & 0.025 & 0.083 & 0.5 & 1 & 75 & 100 \\
\hline 500 & 0.25 & $2 *$ & 75.30 & 0.025 & 0.083 & 0.5 & 1 & 25 & 100 \\
\hline 560 & 0.25 & $2 *$ & 18.87 & 0.025 & 0.083 & 0.5 & 1 & 25 & 75 \\
\hline 600 & $0.25^{*}$ & $2 *$ & $16.00 *$ & 0.025 & 0.083 & 0.5 & 1 & 25 & 75 \\
\hline
\end{tabular}



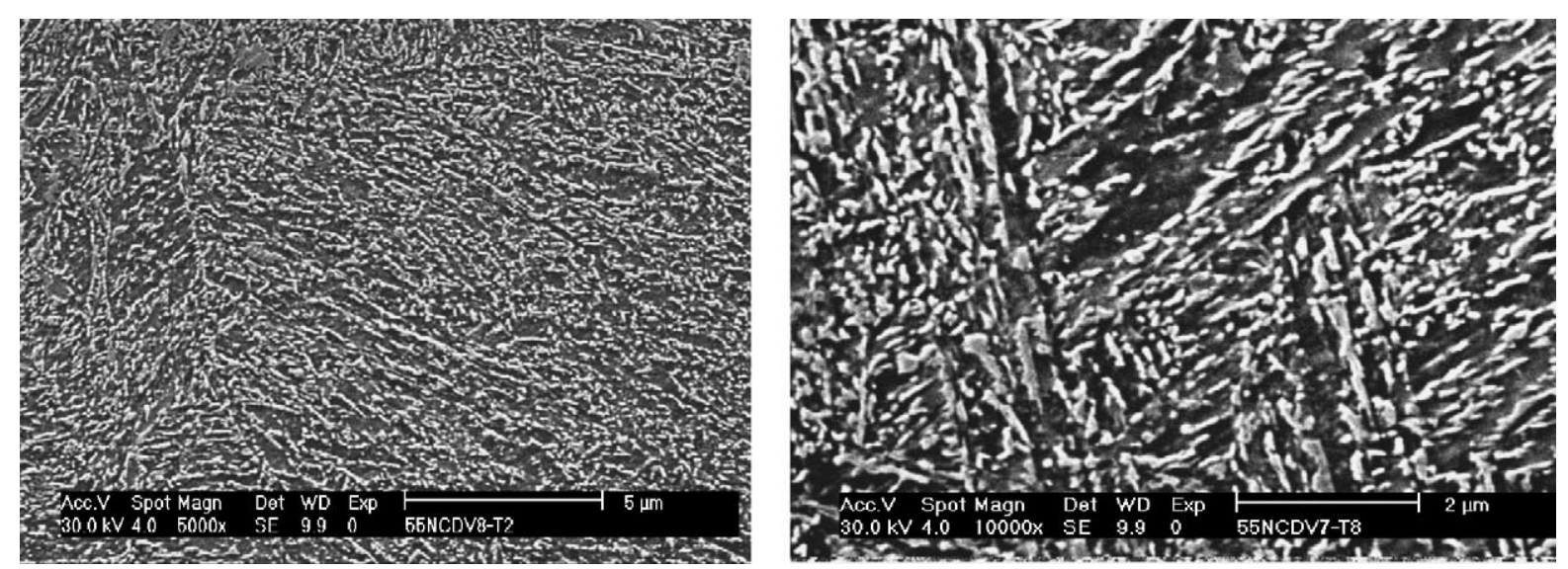

Fig. 2. SEM micrograph of the tempered microstructure showing secondary carbides.
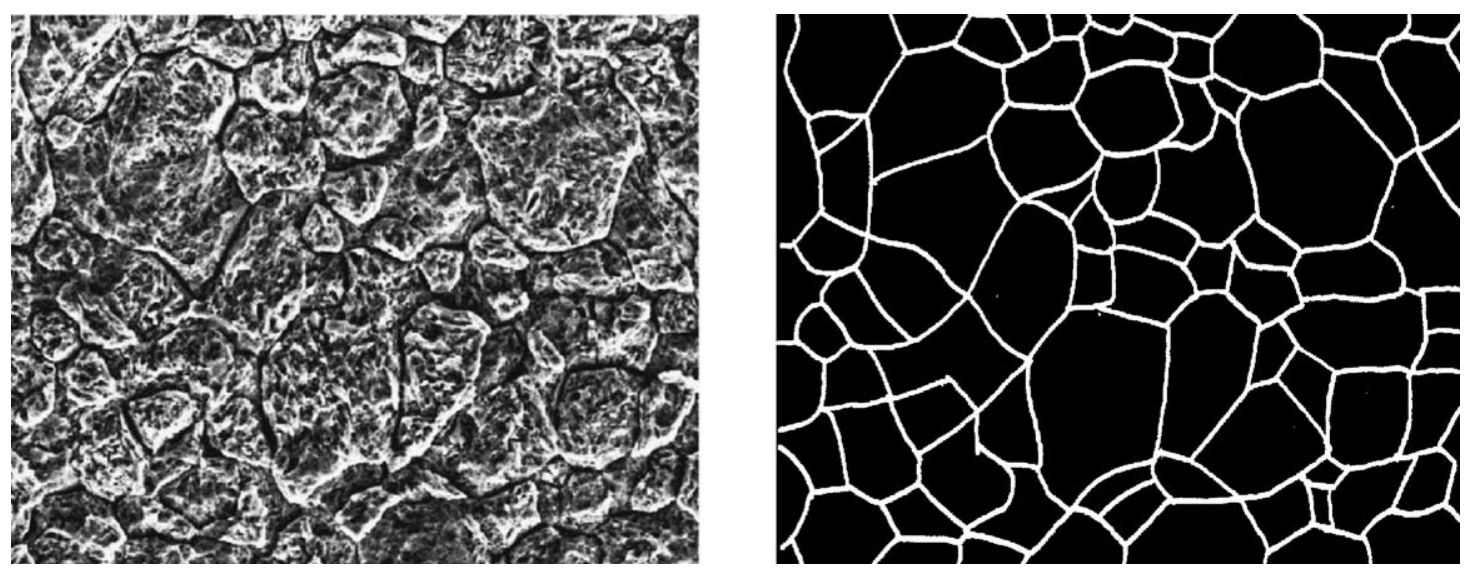

Fig. 3. SEM micrograph of the prior austenitic grains (a) and result of the image analysis (b).

Thirty indentations were performed on each sample with $0.2 \mathrm{~kg}$ load. The mean value was considered as the hardness result. The standard deviation is approximately 10 Vickers $\left(\mathrm{HV}_{0.2}\right)$.

\section{Microstructure evolution during tempering}

Tempering is a diffusion type phase transformation from a quenched martensite to a tempered martensitic structure containing ferrite and carbides as shown in Fig. 2. The precipitation and growth of carbides is strongly related to tempering time and temperature. Therefore, establishing a relation between tempering conditions and microstructures is of great interest. In order to study evolution of microstructural relevant parameters, samples were observed at three different scales.

\subsection{Ex-austenitic grains}

Each sample was observed with SEM and 20 photos with a magnification of 1000 were taken. Grain boundaries were drawn on a tracing paper. Then, the tracing paper was treated with the VISILOG ${ }^{\circledR}$ software as initial photos. These photos were treated by median filtering, entropy thresholding, labeling and finally the perimeter $(P)$ and the area $(S)$ of each grain were calculated. An example of ex-austenitic grain observation and the result of such image treatment are given in Fig. 3.

As the grains are nearly equiaxial, an equivalent diameter $D=4 S / P$ can be calculated. The result of the statistics (Fig. 4) shows that the two samples investigated have nearly the same distribution of grain equivalent diameter. The mean

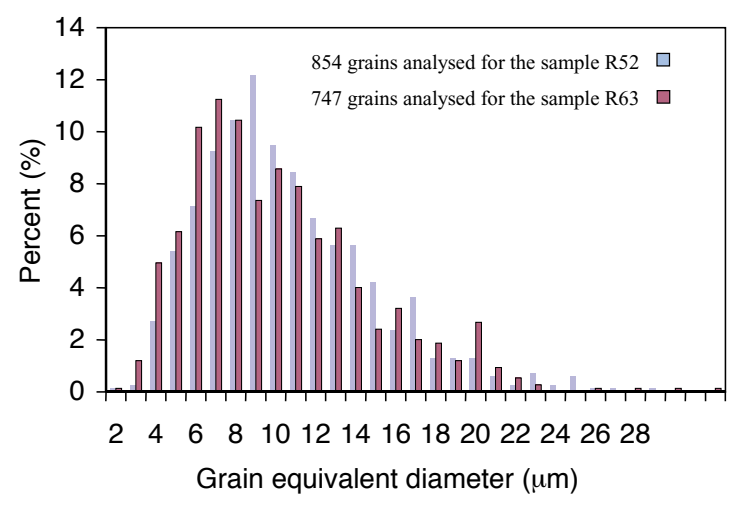

Fig. 4. Distribution of prior austenitic grain equivalent diameters. 

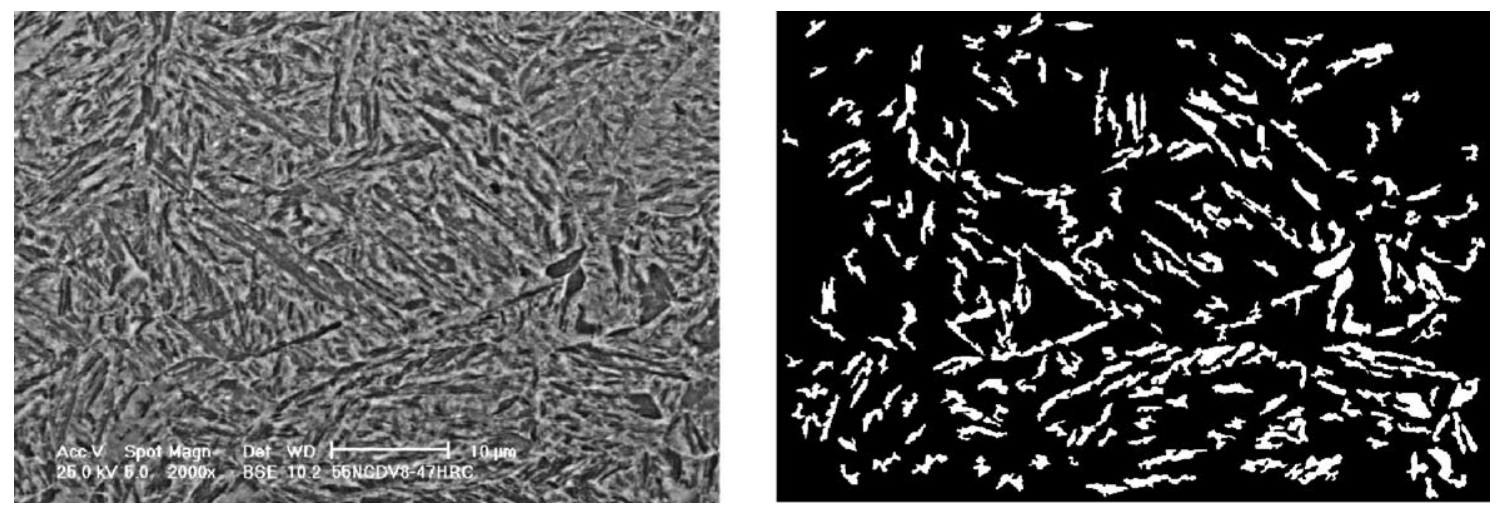

Fig. 5. SEM micrograph of the martensitic laths (a) and result of the image analysis (b).

Table 3

Size and morphology of martensitic laths obtained by image analysis

\begin{tabular}{lllll}
\hline Sample & $\begin{array}{l}\text { Number of } \\
\text { laths analysed }\end{array}$ & $\begin{array}{l}\text { Mean length } \\
\text { of laths }(\mu \mathrm{m})\end{array}$ & $\begin{array}{l}\text { Mean width } \\
\text { of laths }(\mu \mathrm{m})\end{array}$ & $\begin{array}{l}\text { Shape factor } \\
\text { of laths }\end{array}$ \\
\hline R52 & 2540 & 3.49 & 1.64 & 0.47 \\
R63 & 2753 & 3.20 & 1.55 & 0.48 \\
\hline
\end{tabular}

equivalent diameter for samples R52 and R63 are respectively 10.08 and $10.63 \mu \mathrm{m}$, which are nearly the same values as the as-quenched sample. Analyzing Fig. 4 and the data, we found out that the two populations cannot be separated. Therefore, it can be concluded that tempering does not influence the prior austenitic grain size. This conclusion is in agreement with results coming from the literature mainly obtained on carbon steels [17].

\subsection{Martensitic laths}

Each sample was observed on SEM and 10 photos with a magnification of 2000 were taken. These photos were treated with the VISILOG ${ }^{\circledR}$ software through median filtering, entropy thresholding and labeling. An example of martensitic laths observation and the result of such image treatment are given in Fig. 5. Finally, parameters extracted from the image analysis were the length, the width and the shape factor (width/length). Results of the statistics (average values) are

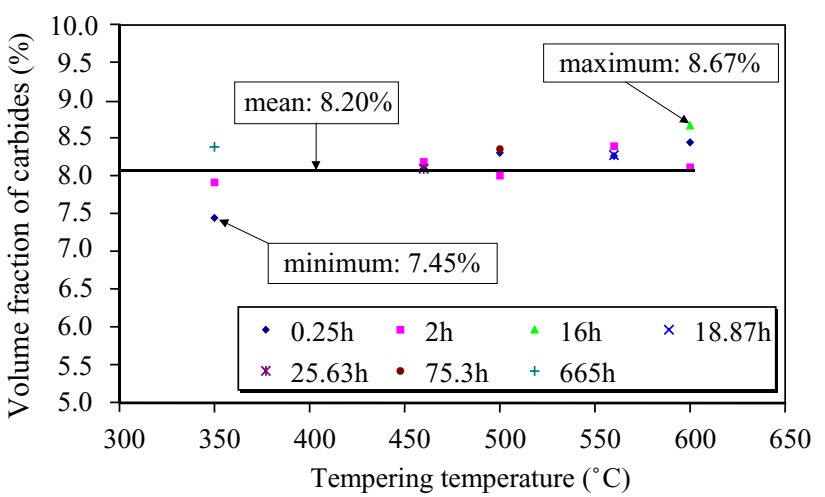

Fig. 7. Evolution of the volume fraction of carbides with the tempering temperature.

presented in Table 3. Distributions of the width and shape factor of martensitic laths are shown in Fig. 6. The conclusion is the same as for prior austenitic grain size. The martensitic lath morphology and size are not influenced by the tempering treatment.

\subsection{Carbides}

The volume fraction of carbides was estimated by XRD with an energy dispersive spectrometer (see Fig. 7). Moreover, TEM observations and image analysis were performed
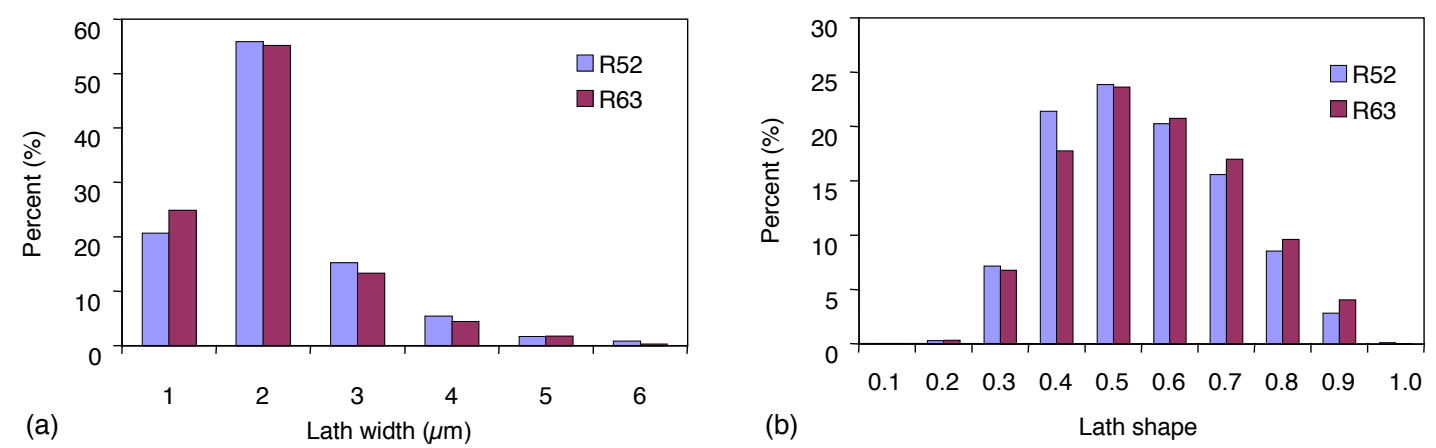

Fig. 6. Distribution of martensitic lath width and shape factor. 


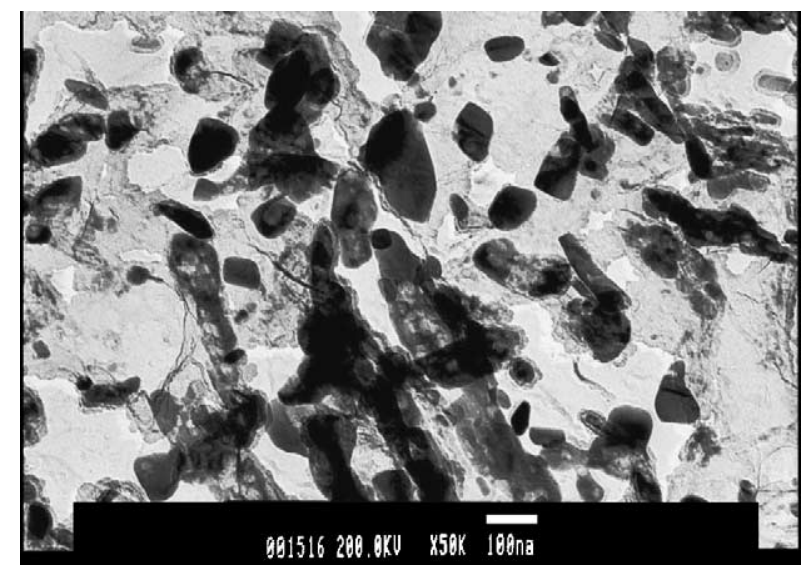

Fig. 8. TEM micrograph of intra-laths carbides extracted from the matrix.

to investigate the evolution of intra-laths carbide size with tempering conditions. Using EDS analysis, the chemical composition of the carbides extracted from the matrix (see Fig. 8) was investigated. Most of the carbides are iron rich carbides, $\mathrm{M}_{3} \mathrm{C}$ type with an orthorhombic structure.

Volume fractions of carbides vary from 7.45 to $8.67 \%$ and the mean value is equal to $8.2 \%$, nearly corresponding to the theoretical maximum volume fraction of cementite assuming that all the carbon has precipitated. Except for $350^{\circ} \mathrm{C}$, where we can see a slight influence of the tempering time in Fig. 7, the volume fraction does not seem to vary with the tempering time and temperature. In conclusion, the volume fraction of carbides can be considered as a constant for these tempering conditions. This conclusion is in agreement with the results given in literature [18].

Six samples (see Table 2) were selected for the evaluation of intra-laths carbides size. The mean intra-laths carbides size, the standard deviation and the $99 \%$ confidence interval on the mean size are reported in Table 4. Confidence intervals were estimated using the $t$-distribution of Student [19]. At a given temperature, the mean size of intra-laths carbide increases rapidly during tempering. When the tempering time increases, the coarsening rate of carbide diminishes. In other respects, for a given tempering time, the mean carbide size increases with tempering temperature, significantly influencing mechanical properties of the steel. Indeed, Fig. 9 shows a strong correlation between the hardness and the average size of carbides.

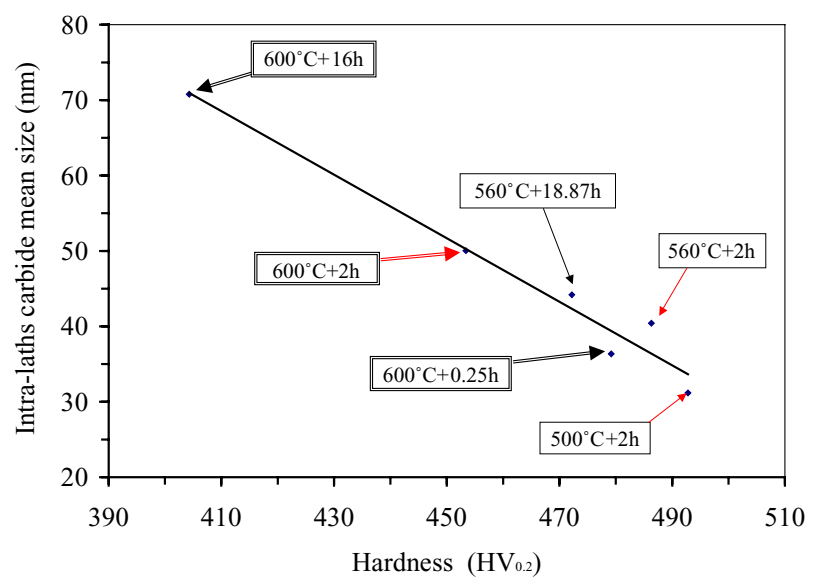

Fig. 9. Relation between hardness and the mean size of intra-laths carbides.

\section{Tempering kinetic law}

\subsection{Definition of a tempering ratio}

Hardness evolutions with tempering time at different temperatures are shown in Fig. 10a and b. A sharp decrease of hardness takes place during the initial stage of tempering at each temperature. Then, this short period is followed by a quasi-linear decrease of hardness, which depends on tempering temperature (see Fig. 11).

Tempering can be considered as a phase transformation promoted by diffusion from an unstable state (martensite) towards a quasi equilibrium state (ferrite + globular carbides). Therefore, all kinds of hardness can be used to define any tempering state between these two states. Nevertheless, hardness cannot clearly indicate the softening from a quenched state or the hardening from an equilibrium state. So, the following definition of a tempering ratio called $\tau_{v}$ is introduced:

$\tau_{v}=\frac{H_{v}-H_{0}}{H_{\infty}-H_{0}}$

where $H_{0}$ is the hardness after quenching, $H_{\infty}$ the hardness in the annealed state, and $H_{v}$ the hardness of an intermediate state between the as-quenched state and the annealed state. According to this definition, tempering ratio values fall between 0 (as-quenched state) and 1 (annealed state). For the $55 \mathrm{NiCrMoV} 7$ steel, the values experimentally obtained

Table 4

Evaluation of the mean size of intra-laths carbides

\begin{tabular}{lclll}
\hline $\begin{array}{l}\text { Tempering } \\
\text { temperature }\left({ }^{\circ} \mathrm{C}\right)\end{array}$ & $\begin{array}{l}\text { Tempering } \\
\text { time }(\mathrm{h})\end{array}$ & $\begin{array}{l}\text { Hardness } \\
\left(\mathrm{HV}_{0.2}\right)\end{array}$ & $\begin{array}{l}\text { Mean size of intra-lath } \\
\text { carbides }(\mathrm{nm})\end{array}$ & $\begin{array}{l}\text { Standard } \\
\text { deviation }(\mathrm{nm})\end{array}$ \\
\hline 600 & 0.25 & 479 & 36.36 & $\begin{array}{l}99 \% \text { confidence interval } \\
\text { on the mean size }(\mathrm{nm})\end{array}$ \\
600 & 2 & 453 & 50.03 & $34.10<d<38.62$ \\
600 & 16 & 404 & 70.78 & 27.15 \\
560 & 2 & 486 & 40.42 & 27.70 \\
560 & 18.87 & 472 & 44.18 & 17.00 \\
500 & 2 & 493 & 31.17 & 36.79 \\
\hline
\end{tabular}



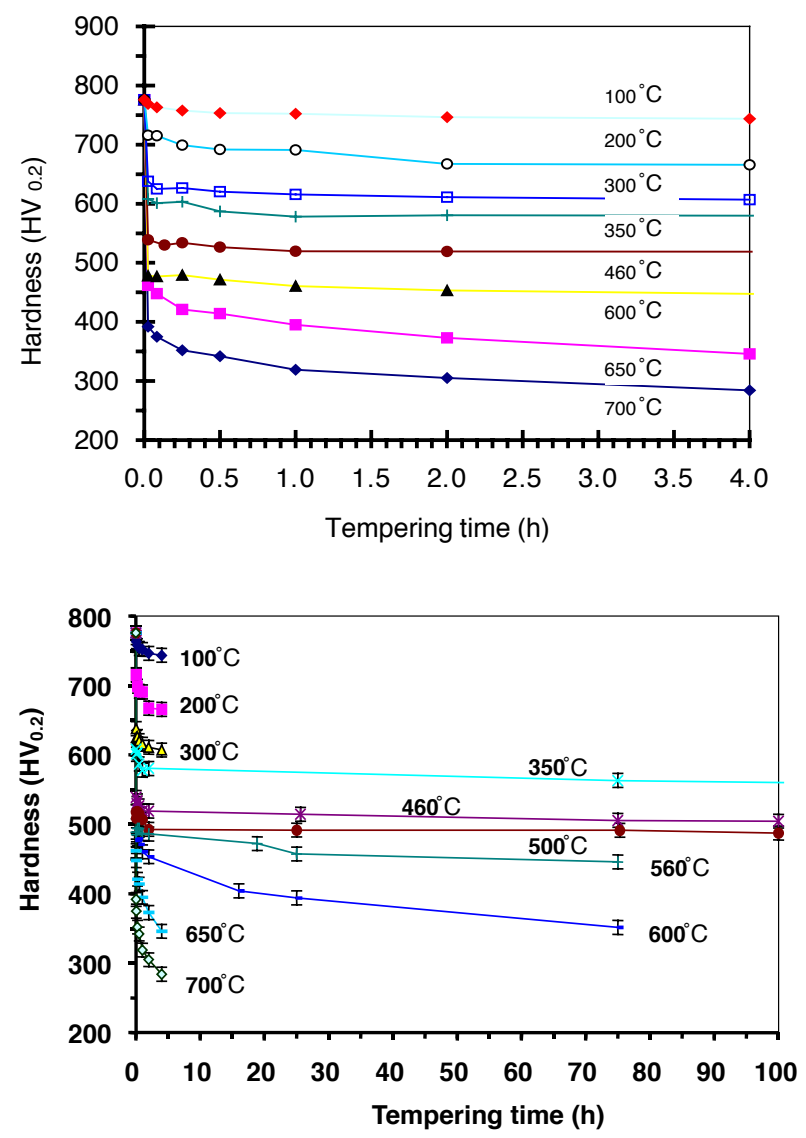

Fig. 10. Hardness evolutions during tempering for different temperatures between 100 and $700^{\circ} \mathrm{C}$.

are respectively $H_{0}=776\left(\mathrm{HV}_{0.2}\right)$ and $H_{\infty}=210\left(\mathrm{HV}_{0.2}\right)$. Evolutions of tempering ratio are shown in Fig. 12. Tempering ratio exponentially increases with the tempering time for various tempering temperatures. The higher the temperature, the greater is the tempering ratio for the same tempering time.

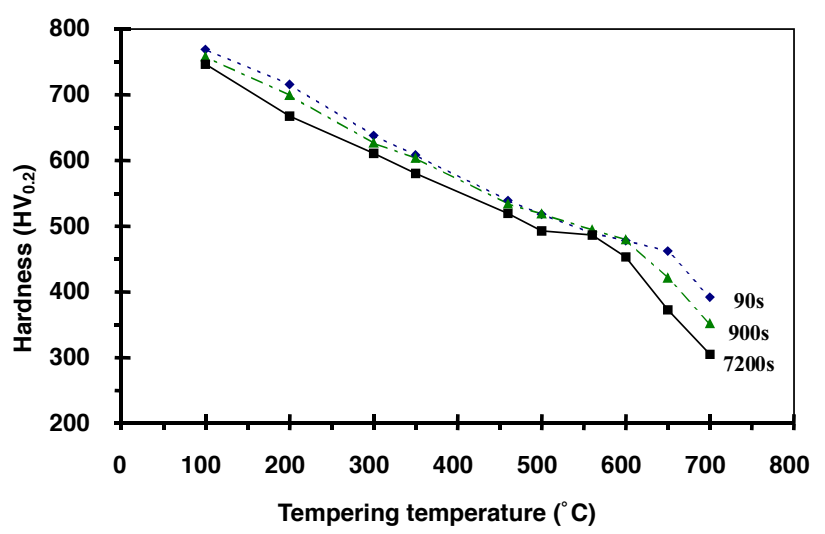

Fig. 11. Influence of tempering temperature on hardness values.
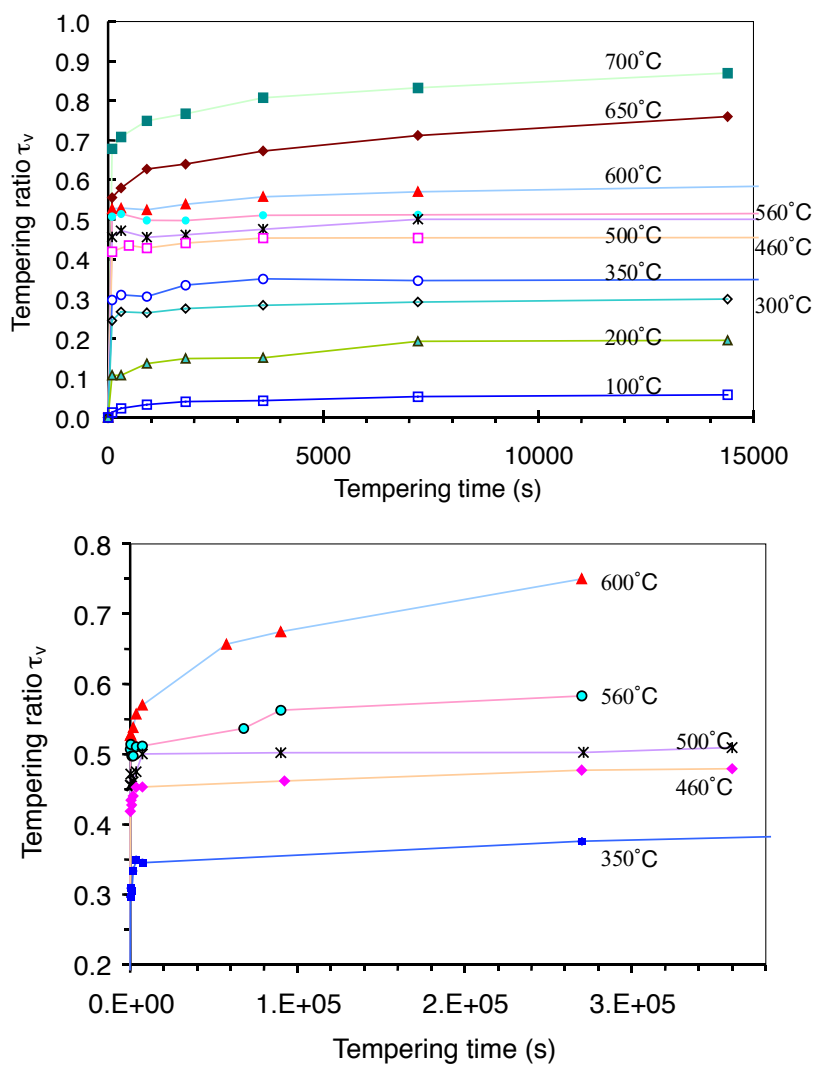

Fig. 12. Evolution of tempering ratio with tempering time and temperature.

\subsection{Tempering kinetic law}

A relation describing solid phase transformation controlled by diffusion was simultaneously proposed by Johnson and Mehl [21], and Avrami [22-24]. This relation is widely used for describing the solid transformation and recrystallization kinetics in metallic materials [20,25-28], and also succeeds in establishing the continuous-cooling transformation (CCT) [29]. As the evolution of the tempering ratio with time and temperature is also controlled by diffusion mechanisms (particularly carbides precipitation and growth), a tempering kinetic law was proposed in the form of the Johnson-Mehl-Avrami type equation as follows:

$\tau_{v}=1-\exp \left(-(D t)^{m}\right)$

where $t$ is the tempering time, $m$ the ageing exponent depending on the material and the previous heat treatment. $D$ depends on tempering temperature and follows the Arrhenius equation:

$D=D_{0} \exp \left(-\frac{Q}{R T}\right)$

where $D_{0}$ is the pre-exponential constant, $Q$ the activation energy of the tempering transformation, $R$ the perfect gas constant (equal to $8.31 \mathrm{~J} \mathrm{~K}^{-1} \mathrm{~mol}^{-1}$ ) and $T$ the tempering temperature in $\mathrm{K}$. 


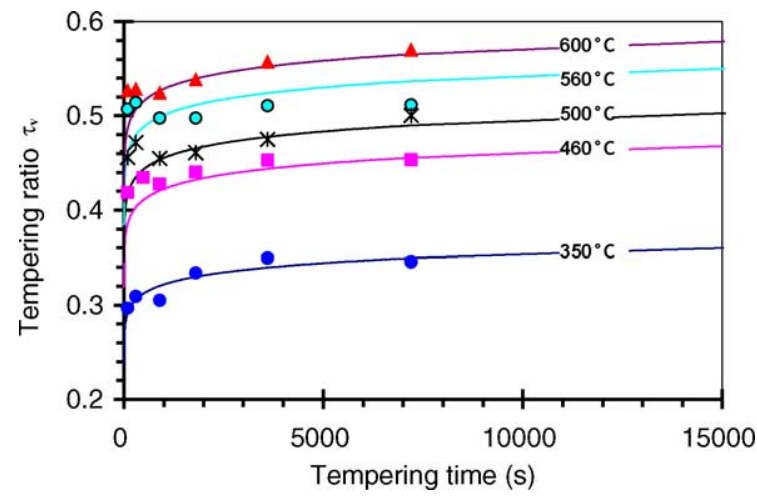

Fig. 13. Evolution of the tempering ratio with time for several temperatures between 350 and $600^{\circ} \mathrm{C}$ : experimental results and predictions obtained with the kinetic law.

Introducing Eq. (2) into Eq. (3), the tempering hardness can be expressed by the following equations:

$H_{v}=H_{0}+\left(H_{\infty}-H_{0}\right)\left(1-\exp \left(-(D t)^{m}\right)\right.$

or

$H_{v}=H_{\infty}+\left(H_{0}-H_{\infty}\right) \exp \left(-(D t)^{m}\right)$

Using the measured hardness values, parameters were identified with a method consisting in minimizing the difference between the experience and the simulation using the software SiDoLo [30]. The obtained values are respectively $D_{0}=2.7 \times 10^{8} \mathrm{~s}^{-1}, m=0.0518$ and $Q \approx 231 \mathrm{~kJ} \mathrm{~mol}^{-1}$. The latter value is close to the values reported in literature for low or medium alloyed steel and also close to the activation energy of the diffusion of usual alloying elements $(\mathrm{Cr}$, $\mathrm{Mn}, \mathrm{Ni}, \mathrm{V})$ in ferrite [31]. Fig. 13 shows the experimental and calculated evolution of tempering ratio for short times ( $\leq 4 \mathrm{~h}$ ) corresponding to the domain of usual industrial tempering conditions. When complex time-temperature routes are followed, a differential equation of the kinetic law has to be used:

$\dot{\tau}_{v}=\left(1-\tau_{v}\right) m D\left(\ln \frac{1}{1-\tau_{v}}\right)^{m-1 / m}$

where: if $t=0, \tau_{v}=0$, then $\dot{\tau}_{v} \rightarrow \infty$ and if $\tau_{v}=1$, $t \rightarrow \infty$, then $\dot{\tau}_{v} \rightarrow 0$, as shown in Fig. 13 .

\subsection{Validation}

To validate the tempering kinetic law, three sets of double tempering (complex time-temperature routes) were performed. Results are presented in Fig. 14 where a comparison between experimental results and predictions obtained with the proposed kinetic law is done. Experimental results closely agree with predicted values. After a first tempering at $350{ }^{\circ} \mathrm{C}(1 \mathrm{~h})$, the steel strongly softens when the second tempering temperature is higher than the first tempering one. On the contrary, the steel softens very slowly when the temperature of second tempering is less than the first one.

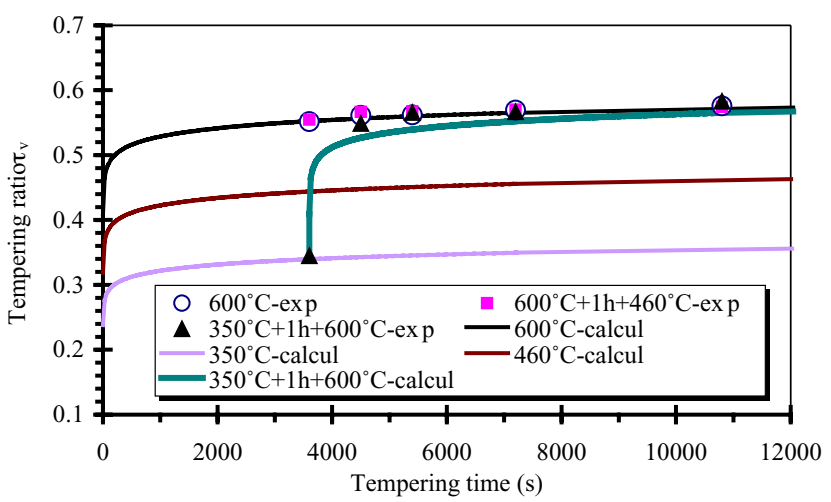

Fig. 14. Evolution of the tempering ratio with time for a double tempering: experimental results and predictions obtained with the kinetic law.

If the tempering temperature remains constant, the behavior of the steel during the second tempering follows closely the situation obtained at the end of the first one. Therefore, the proposed kinetic law (Eq. (7)) seems to be valid for the steel investigated.

\section{Discussion}

\subsection{Relationship with the Hollomon-Jaffe tempering relation}

According to Eq. (6), various tempering routes can be followed to reach the same hardness value $\mathrm{H}_{\mathrm{V}}$. For example, for two different routes:

$t_{1} \exp \left(\frac{Q}{R T_{1}}\right)=t_{2} \exp \left(\frac{Q}{R T_{2}}\right)=$ constant

and more generally:

$t \exp \left(-\frac{Q}{R T}\right)=$ constant

Consequently, Eq. (9) leads to the well-known HollomonJaffe relation:

$T(k+\log t)=\mathrm{constant}$

Compared to the Hollomon-Jaffe relation, the proposed kinetic law gives an explicit relation between hardness, time and tempering temperature. It can properly point out metallurgical mechanisms associated to the strong hardness decrease at the beginning of the tempering and to the following slow softening.

\subsection{Application to other steels}

Using the data found in the literature $[4,7,10]$, the kinetic law was applied to other steels. The selection was done assuming that carbides found in these low-alloyed steels are iron rich carbides (cementite) as in the $55 \mathrm{NiCrMoV7}$. Steels investigated and parameters obtained are shown in 
Table 5

Parameters of the tempering law obtained for different steels selected in the literature

\begin{tabular}{|c|c|c|c|c|c|c|}
\hline Reference & Author & Steel & $\begin{array}{l}\text { Activation energy } \\
Q\left(\mathrm{~J} \mathrm{~mol}^{-1}\right)\end{array}$ & $\begin{array}{l}\text { Ageing } \\
\text { exponent, } m\end{array}$ & $\begin{array}{l}\text { Frequency factor } \\
D_{0} \times 10^{8}\left(\mathrm{~s}^{-1}\right)\end{array}$ & $\begin{array}{l}\text { Hardness for the } \\
\text { as-quenched steel }\end{array}$ \\
\hline \multirow[t]{6}{*}[10]{} & \multirow[t]{6}{*}{ Hollomon and Jaffe } & Steel-R (0.98C, 0.3Mn, 0.3Si) & 201225 & 0.141 & 3.929 & $66.5(\mathrm{HRc})$ \\
\hline & & Steel-S (0.56C, $0.54 \mathrm{Mn}, 0.18 \mathrm{Si})$ & 219853 & 0.115 & 37.982 & 63(HRc) \\
\hline & & Steel-T (0.74C, $0.66 \mathrm{Mn}, 0.18 \mathrm{Si})$ & 221105 & 0.113 & 13.362 & $66.5(\mathrm{HRc})$ \\
\hline & & Steel-U $(0.31 \mathrm{C}, 0.52 \mathrm{Mn}, 0.1 \mathrm{Si})$ & 237731 & 0.127 & 1263.709 & 46.5(HRc) \\
\hline & & Steel-V (1.15C, 0.58Mn, 0.09Si) & 201238 & 0.122 & 0.711 & 64.5(HRc) \\
\hline & & Steel-W (0.89C, $0.55 \mathrm{Mn}, 0.06 \mathrm{Si})$ & 212974 & 0.107 & 3.036 & 67(HRc) \\
\hline$[4]$ & Engel & Steel-E (0.94C, $0.4 \mathrm{Mn}, 0.133 \mathrm{Si})$ & 219932 & 0.133 & 2490.728 & $682(\mathrm{BHN})$ \\
\hline [7] & Murphy & Steel-M (0.39C, $0.71 \mathrm{Mn}, 0.22 \mathrm{Si})$ & 196888 & 0.109 & 51.111 & $608(\mathrm{VPN})$ \\
\hline
\end{tabular}

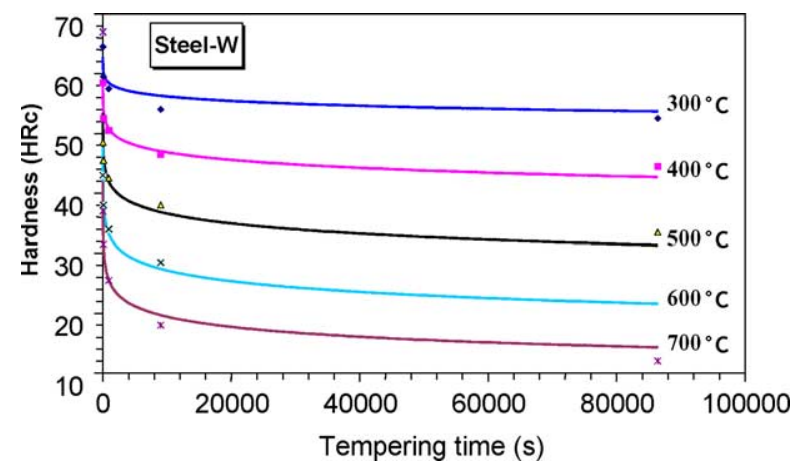

Fig. 15. Comparison between experimental and calculated hardness for the Steel-W.

Table 5. An example of comparison between experimental results and calculated hardness is presented in Fig. 15 for the Steel-W. Therefore, the kinetic law proposed in this paper seems to be widely suitable for the description of the transformation process from a non-equilibrium state towards an equilibrium state. As it is a kinetic law, this law could be used to predict the hardness evolution of a tool when it is under ageing effect. Nevertheless, the application of the law to more alloyed steels with an intensive precipitation of special carbides (with a sharp secondary peak hardening) is now under discussion. More generally, the effects of alloying additions and austenitizing treatments on secondary hardening constitute an interesting outlook of this study.

\section{Conclusions}

The tempering behavior of the $55 \mathrm{NiCrMoV} 7$ steel was investigated describing microstructural and associate hardness evolutions. Main results are summarized below:

(1) The morphology and size of the ex-austenitic grain and the martensitic lath, at selected magnification and method of observation, are not significantly influenced during the tempering of the $55 \mathrm{NiCrMoV} 7$ steel. The volume fraction of carbides, estimated by X-ray diffraction, also remains constant for a tempering between 350 and $600{ }^{\circ} \mathrm{C}$ for a large range of time.
(2) Conversely, the morphology and size of observed carbides are strongly modified with tempering conditions. TEM observations have shown an increase of the mean size of mostly iron carbides with tempering temperature and time. A linear relation between hardness and the mean size of carbides has been observed.

(3) Based on the hardness of quenched state, tempered state and annealed state, a tempering ratio has been defined. Then, a kinetic law of tempering controlled by solid state diffusion has been proposed. This kinetic law can well describe the evolution of all types of hardness (Vickers, Rockwell, etc.) with temperature and time during the tempering of martensitic steel.

\section{Acknowledgements}

The authors would like to thank the Thyssen France Company for supplying the steel investigated and the China Scholarship Council for financial support.

\section{References}

[1] R. Komanduri, Z.B. Hou, Int. J. Mech. Sci. 43 (2001) 57.

[2] C.L. Gibbons, J.E. Dunn, Ind. Heat. 47 (1980) 6.

[3] G. Andreis, K.-D. Fuchs, I. Schruff, in: F. Jeglitsch, R. Ebner, H. Leitner (Eds.), Proceedings of the Fifth International Conference on Tooling, Tool Steels in the Next Century, University of Leoben, Austria, 29 September to 1 October 1999, p. 593.

[4] E.H. Engel, Trans. Am. Soc. Met. 27 (1939) 17.

[5] K. Kuo, J. Iron Steel Inst. 173 (1953) 375.

[6] R.G. Baker, J. Nutting, J. Iron Steel Inst. 179 (1959) 268.

[7] S. Murphy, J.H. Woodhead, Metall. Trans. 3 (1972) 735.

[8] K.J. Irvine, F.B. Pickering, J. Iron Steel Inst. 180 (1960) 153.

[9] B.K. Jha, N.S. Mishra, Mater. Sci. Eng. A 263 (1999) 55.

[10] J.H. Hollomon, L.D. Jaffe, Trans. AIME 162 (1945) 249.

[11] G. Murry, R. Namdar, Revue de Metallurgie 7/8 (1970) 670.

[12] G. Murry, Revue de Metallurgie 12 (1977) 672.

[13] J. Barralis, G. Maeder, in: A. Nathan (Ed.), Le précis de métallurgie, élaboration, structure-propiétés et normalisation, 1991.

[14] E. Smith, J. Nutting, J. Iron Steel Inst. 177 (1957) 329.

[15] S. Jean, Ph.D.Thesis, Institut national polytechnique de Toulouse, 1999.

[16] N. Mebarki, Ph.D. Thesis, Ecole Nationale Supérieure des Mines de Paris, February 2003. 
[17] A.V. Sverdlin, A.R. Ness, in: G.E. Totten, M.A.H. Howes (Eds.), Fundamental Concepts in Steel Heat Treatment, Steel Heat Treatment Handbook, Marcel Dekker, 1997, pp. 1-44.

[18] M.F.Ashby, D.R.H. Jones, Matériaux, 2: Microstructure et mise en oeuvre, Dunod, Paris, 1991.

[19] W.S. Gosset, in: E.S. Pearson, J. Wishart (Eds.), The Probable Error of a Mean, "Student's" Collected Papers, Cambridge: University Press, 1958.

[20] G. Béranger, G.Henry, G.Sanz, Le Livre De L'acier, Technique \& Documentation, Lavoisier, Paris, 1994.

[21] W.A. Johnson, R.F. Mehl, Trans. Am. Inst. Mining, Metall. Petroleum Eng. Incorporated 135 (1939) 458.
[22] M. Avrami, J. Chem. Phys. 7 (1939) 1112.

[23] M. Avrami, J. Chem. Phys. 8 (1940) 224.

[24] M. Avrami, J. Chem. Phys. 9 (1941) 184.

[25] J. Majta, J.G. Lenard, M. Pietrzyk, ISIJ Int. 36 (1996) 1102.

[26] A. Borrego, G.G. Doncel, Mater. Sci. Eng. A 252 (1998) 152.

[27] M. Takahashi, H.K.D.H. Bhadeshia, Mater. Sci. Technol. 6 (1990) 603.

[28] T. Tsuchiyama, Y. Miyamoto, S. Takaki, ISIJ Int. 41 (2001) 1052.

[29] ASM Handbook, Volume 4: Heat Treating, ASM International, 1991.

[30] P. Pilvin, SiDoLo, Notice d'utilisation, 1985.

[31] Z. Zhang, Ph.D Thesis, Ecole Nationale Supérieure des Mines de Paris, May 2002. 